\title{
Is Long-term Ambient Air Pollutant Exposure a Risk Factor for Irritable Bowel Syndrome in Children? A 12-year Longitudinal Cohort Study
}

\begin{abstract}
Teck-King Tan, ${ }^{1}$ Miguel Saps, ${ }^{2}$ Cheng-Li Lin, ${ }^{3,4}$ and Chang-Ching Wei ${ }^{5,6 *}$
${ }^{1}$ Division of Pediatric Gastroenterology, Department of Pediatrics, Children's Hospital, China Medical University Hospital, Taichung, Taiwan; ${ }^{2}$ Division of Pediatric Gastroenterology, Hepatology and Nutrition, Department of Pediatrics, University of Miami Health System, FL, USA; ${ }^{3}$ Management Office for Health Data, China Medical University Hospital, Taichung, Taiwan; ${ }^{4}$ Department of Public Health, China Medical University, Taichung, Taiwan; ${ }^{5}$ Division of Pediatric Allergy, Immunology, and Rheumatology, Department of Pediatrics, Children's Hospital, China Medical University Hospital, Taichung, Taiwan; and ${ }^{6}$ School of Medicine, China Medical University, Taichung, Taiwan
\end{abstract}

\section{Background/Aims}

Recent studies suggest that air pollution may play a role in gastrointestinal disorders. However, the effect of long-term exposure to air pollution on childhood irritable bowel syndrome (IBS) is unclear. Hence, we conducted a nationwide cohort study to investigate the association between long-term air pollution exposure and the incidence and risk of IBS in Taiwanese children during 2000-2012.

\section{Methods}

We collected data from the Taiwan National Health Insurance Research Database, linked to the Taiwan Air Quality-Monitoring Database according to the insurant living area and the air quality-monitoring station locations. Children $<18$ years old, identified from January 1st, 2000, were followed-up until IBS diagnosis or December 31st, 2012. The daily average air pollutant concentrations were categorized into 4 quartile-based groups (Q1-Q4). We measured the incidence rate, hazard ratios (HRs), and 95\% confidence intervals for IBS stratified by the quartiles of air pollutant concentration.

\section{Results}

A total of 3537 children (1.39\%) were diagnosed with IBS within the cohort during the follow-up period. The incidence rate for IBS increased from 0.84 to 1.76 , from 0.73 to 1.68 , from 0.85 to 1.98 , and from 0.52 to 3.22 per 1000 person-years, with increase in the carbon monoxide, nitrogen dioxide, non-methane hydrocarbon, and methane quartile (from Q1 to Q4) exposure concentration, respectively. The adjusted HR for IBS increased with elevated carbon monoxide, nitrogen dioxide, non-methane hydrocarbon, and methane exposure in Q4 to $1.98,2.14,2.19$, and 5.87, respectively, compared with Q1.

\section{Conclusion}

Long-term ambient air pollutant exposure is an environmental risk factor for childhood IBS.

(J Neurogastroenterol Motil 2019;25:241-249)

Key Words

Air pollutant; Child; Irritable bowel syndrome; Follow-up studies

\section{Received: August 3, 2018 Revised: November 27, 2018 Accepted: March 4, 2019}

(a) This is an Open Access article distributed under the terms of the Creative Commons Attribution Non-Commercial License (http://creativecommons. org/licenses/by-nc/4.0) which permits unrestricted non-commercial use, distribution, and reproduction in any medium, provided the original work is properly cited.

*Correspondence: Chang-Ching Wei, MD

Division of Pediatric Allergy, Immunology, and Rheumatology, Department of Pediatrics, Children's Hospital, China Medical University Hospital, School of Medicine, China Medical University, No. 2, Yu-Der Road, Taichung 40402, Taiwan Tel: +886-4-22052121-4639, Fax: +886-4-2203-2798, E-mail: weilonger@gmail.com 


\section{Introduction}

Irritable bowel syndrome (IBS), which is the most common diagnosis in children with functional abdominal pain disorders, has become an important issue worldwide. ${ }^{1}$ Childhood IBS may cause deterioration of children's quality of life, increase in medical costs, lower social and school performance, and increase the risk of subsequent psychiatric disorders. ${ }^{2}$ The prevalence of pediatric IBS could be as high as $20 \%$ in some populations, ${ }^{3,4}$ and up to $45 \%$ in some hospital-based populations. ${ }^{5,6}$

The pathogenesis of IBS is multifactorial, including visceral hypersensitivity, intestinal motility disturbance, intestinal inflammation, intestinal microbiome dysbiosis, food hypersensitivity, and psychological distress. ${ }^{7}$ However, a number of pediatric IBS cases could not be explained by these mechanisms, and the causative factors of the symptoms are still not well understood.

Air pollution has become an increasingly important issue due to its adverse impact on public health. While classical studies of air pollution focused on respiratory and cardiovascular disorders, ${ }^{8}$ recent studies suggested that air pollution may play a role in several gastrointestinal (GI) disorders, such as inflammatory bowel disease, ${ }^{9}$ enterocolitis, ${ }^{10}$ and functional abdominal pain. ${ }^{11}$ Some evidence suggests inhalation of fine particles, or air pollution from coal industry, may disrupt the immune system and trigger gut inflammation by increasing gut permeability and altering gut microbiota. ${ }^{9}$ The interplay between the gut microbiome and the immune system may influence the development of IBS. ${ }^{4,7}$ Therefore, we investigated whether long-term ambient air pollutant exposure was an environmental risk factor for childhood IBS.

\section{Materials and Methods}

\section{Data Source}

The Taiwan National Health Insurance Research Database (NHIRD), an electronic claim database of the Taiwan National Health Insurance (NHI) program, covers $99 \%$ of the 25 million population of Taiwan and contracts with more than $90 \%$ of national health care facilities (https://nhird.nhri.org.tw/en/index.html). ${ }^{12,13}$ The high reliability of the diagnostic data from the NHIRD has been evaluated in previous studies. ${ }^{12,14}$ The NHIRD includes detailed information, such as outpatient visits, hospital admissions, prescriptions, procedures, and diagnosis of disease based on the International Classification of Diseases, Ninth Revision, Clinical
Modification (ICD-9-CM) ${ }^{14}$ Every individual in Taiwan has a unique personal identification number. The data on patient identities were scrambled cryptographically by the NHIRD to protect patient privacy. ${ }^{12,14}$ All NHI datasets can be interlinked with the personal identification number of everyone. This study utilized a data file (the Children file) derived from the NHIRD, containing information from half of all insured children in Taiwan, chosen at random. ${ }^{15}$ The dataset provided an adequate sample size to pursue the objectives addressed in this study. This study has been approved by the Institute Review Board of China Medical University Hospital (CRREC-103-048), and it complies with the principles outlined in the Declaration of Helsinki.

\section{Study Population, Endpoints, Outcome of Interest, and Confounding Factors}

This was a retrospective cohort study. We formed a child cohort by selecting individuals aged $<18$ years in 2000-2012 and those who had diagnosed with IBS before were excluded. All individuals in this cohort were followed from baseline until either the first diagnosis of IBS, death, termination of insurance, or at the end of 31 December 2012. Individuals who had missing information such as their address, sex, and air pollution data were also excluded. The final study population contained 254207 individuals. We identified individuals who received at least 2 consensus diagnoses of IBS (ICD-9-CM code 564.1) between 1 January 2000 and 31 December 2012 made by gastroenterologists. We defined newly diagnosed IBS as the first diagnosis of IBS. In this study, the mean follow-up years in IBS patients were 10.8 (SD, 2.84). The confounding factors were age, sex, monthly income, urbanization level of residence, number of consultations/visits with a physician per year, and allergy diseases. Allergy diseases were defined as having atopic dermatitis (ICD-9-CM code 691 or 691.8), allergic rhinitis (ICD-9-CM code 477) and/or asthma (ICD-9-CM code 493). The residential areas of the study subjects, which covered 365 Taiwan townships, were classified into seven levels of urbanization according to the method developed by Liu et al. ${ }^{16}$ Level 1 was referring to the "most urbanized" and level 7 was referring to the "least urbanized" communities. The variables used in developing the township stratification for urbanization level consisted of the population density (people $/ \mathrm{km}^{2}$ ), population ratio of people with an educational level of college or above, population ratio of elder people over 65 years old, population ratio of agricultural workers, and the number of physicians per 100000 people, among others. ${ }^{16}$ As there were very small numbers of IBS cases at levels 4, 5, 6, and 7, these 4 levels were combined into a single group (Level 4). Therefore, the urbanization 
level was stratified into four levels, from the highest density (Level 1) to the lowest density (Level 4). Monthly income was classified into 4 groups; < New Taiwan dollar (NT\$)14 400, NT\$14 400$18300, \mathrm{NT} \$ 18301-21000$, and $>\mathrm{NT} \$ 21000$.

\section{Exposure Measurement}

The Taiwan Air Quality Monitoring Network (TAQMN) (http:/taqm.epa.gov.tw/taqm/en/PsiMap.aspx) was established by the Taiwan Environmental Protection Administration (TEPA) in 1993 (http://www.epa.gov.tw/). TAQMN consists of 74 monitoring stations, which were fully automated and provided daily readings of air pollutants all over Taiwan. The Taiwan Air QualityMonitoring Database (TAQMD) were released by the Taiwan Environmental Protection Agency, Executive Yuan during 19982012. The TAQMD contains the daily concentrations of carbon monoxide $(\mathrm{CO})$, nitrogen dioxide $\left(\mathrm{NO}_{2}\right)$, non-methane hydrocarbon $(\mathrm{NMHC})$, and methane $\left(\mathrm{CH}_{4}\right)$. The children file from NHIRD and TAQMD were linked according to the residential areas of insurants and the areas where the air quality-monitoring stations were located. ${ }^{17}$ The residential area for each insured child was defined based on the sought treatment for common cold (acute nasopharyngitis: ICD-9-CM code 460). A daily average air pollutant concentration was calculated by dividing the cumulative daily air pollutant concentration by the duration from 2000 to the endpoint for each study participant. The daily average air pollutant concentrations were categorized into 4 groups based on quartiles, namely Q1, Q2, Q3, and Q4. CO was categorized as Q1 $(<0.56$ parts per million [ppm]), Q2 (0.56-0.67 ppm), Q3 (0.68-0.81 $\mathrm{ppm})$, and Q4 (>0.81 ppm). $\mathrm{NO}_{2}$ concentration was categorized as Q1 (< 18.3 parts per billion [ppb]), Q2 (18.3-23.6 ppb), Q3 (23.7-26.9 ppb), and Q4 (> $26.9 \mathrm{ppb).} \mathrm{NMHC} \mathrm{was} \mathrm{categorized}$ as Q1 (<0.27 ppm), Q2 (0.27-0.34 ppm), Q3 (0.35-0.50 ppm), and Q4 $(>0.50 \mathrm{ppm})$. $\mathrm{CH}_{4}$ was categorized as Q1 $(<2.01 \mathrm{ppm})$, Q2 (2.01-2.05 ppm), Q3 (2.06-2.11 ppm), and Q4 (> $2.11 \mathrm{ppm})$.

\section{Statistical Methods}

The sociodemographic factors in the current study included age, sex, monthly income, urbanization level of residential area, and daily average of exposure air pollutants. To test the distributed difference among daily average concentrations for each air pollutant by quartile and urbanization, chi-square test was used. The KaplanMeier method was used to estimate the cumulative incidence of IBS during the follow-up period among the different quartiles of each air pollutant. The incidence density rate of IBS (per 1000 person-years) was calculated by each quartile of daily average con- centrations among the 4 air pollutants. Cox proportional hazard regression was used to estimate the hazard ratios (HRs) and 95\% confidence interval (CIs) for IBS in Q2-Q4 level for air pollutant concentration compared the lowest one (Q1). Multivariable model was adjusted for age, sex, monthly income, urbanization level, number of consultations/visits with a physician per year, and allergy diseases. All analyses were performed using SAS 9.3 (SAS Institute Inc, Cary, NC, USA) and the Statistical Package for the Social Science (version 15.1; IBM Corp, Armonk, NY, USA). All statistical tests were considered statistically significant when 2 -tailed $P$-values were $<0.05$.

\section{Results}

A total of 3537 children (1.39\%) were diagnosed with IBS

Table 1. Baseline Demographics and Exposure of Air Pollutants Exposure by Daily Average Concentration in Taiwan Children ( $\mathrm{N}=$ $254207)$

\begin{tabular}{lr}
\hline \multicolumn{1}{c}{ Characteristics of study population } & \multicolumn{1}{c}{ Values } \\
\hline Gender & \\
Boys & $131223(51.6)$ \\
Girls & $122984(48.4)$ \\
Age (yr) & $6.43 \pm 3.38$ \\
Urbanization level & \\
1 & $84679(33.3)$ \\
2 & $81371(32.0)$ \\
3 & $48142(18.9)$ \\
4 & $40015(15.7)$ \\
Allergic diseases & \\
No & $220682(86.8)$ \\
Yes & $33525(13.2)$ \\
Average number of consultations/visits with a & $12.8 \pm 7.96$ \\
physician per year & \\
Exposure of air pollutants (daily average) & \\
CO level (ppm) & $0.79 \pm 0.27$ \\
NO$_{2}$ level (ppb) & $24.5 \pm 5.58$ \\
$\mathrm{NMHC}^{\mathrm{a}}$ level (ppm) & $0.39 \pm 0.17$ \\
$\mathrm{CH}_{4}$ (ppm) & $2.03 \pm 0.13$ \\
Outcome & $3537(1.39)$ \\
Irritable bowel syndrome (yes) & $10.8 \pm 2.84$ \\
Follow-up periods (yr) & \\
\hline
\end{tabular}

${ }^{a}$ The urbanization level was categorized by the population density of the residential area into 4 levels, with level 1 as the most urbanized and level 4 as the least urbanized.

${ }^{b}$ Having any one of allergic diseases, including atopic dermatitis, allergic rhinitis, and asthma.

$\mathrm{CO}$, carbon monoxide; $\mathrm{NO}_{2}$, nitrogen dioxide; $\mathrm{NMHC}$, non-methane hydrocarbon; $\mathrm{CH}_{4}$, Methane; ppm, parts per million; ppb, parts per billion.

Values were expressed as $\mathrm{n}(\%)$ or mean $\pm \mathrm{SD}$. 
Table 2. Baseline Urbanization Level Among Quartiles of Daily Average Concentration of Air Pollutants in Taiwan Children ( $\mathrm{N}=254$ 207)

\begin{tabular}{|c|c|c|c|c|c|}
\hline \multirow{2}{*}{ Air pollutant concentration } & \multicolumn{4}{|c|}{ Urbanization level } & \multirow{2}{*}{$P$-value } \\
\hline & 1 & 2 & 3 & 4 & \\
\hline Carbon monoxide & & & & & $<0.001$ \\
\hline Q1 & $4696(14.6)$ & $8961(27.9)$ & $6862(21.3)$ & $11651(36.2)$ & \\
\hline Q2 & $12575(20.6)$ & $25469(41.7)$ & $11668(19.1)$ & $11409(18.7)$ & \\
\hline Q3 & $27722(35.4)$ & $21783(27.8)$ & $17805(22.7)$ & $11084(14.1)$ & \\
\hline Q4 & $39686(48.1)$ & $25158(30.5)$ & $11807(14.3)$ & $5871(7.1)$ & \\
\hline Nitrogen dioxide & & & & & $<0.001$ \\
\hline Q1 & $4765(13.0)$ & $11919(32.5)$ & $5248(14.3)$ & $14702(40.1)$ & \\
\hline Q2 & $13605(21.9)$ & $20584(33.2)$ & $14101(22.7)$ & $13764(22.2)$ & \\
\hline Q3 & $23255(32.3)$ & $26236(36.5)$ & $16434(22.8)$ & $6060(8.42)$ & \\
\hline Q4 & $43054(51.5)$ & $22632(27.1)$ & $12359(14.87)$ & $5489(6.6)$ & \\
\hline Non-methane hydrocarbon & & & & & $<0.001$ \\
\hline Q1 & $10790(18.8)$ & $16860(29.4)$ & $9088(15.8)$ & $20650(36.0)$ & \\
\hline Q2 & $20824(26.5)$ & $27181(34.6)$ & $19826(25.2)$ & $10732(13.7)$ & \\
\hline Q3 & $25749(46.7)$ & $15770(28.6)$ & $9423(17.1)$ & $4166(7.56)$ & \\
\hline Q4 & $27316(43.3)$ & $21560(34.1)$ & $9805(15.5)$ & $4467(7.1)$ & \\
\hline Methane & & & & & $<0.001$ \\
\hline Q1 & $18580(30.6)$ & $15627(25.7)$ & $14990(24.7)$ & $11569(19.0)$ & \\
\hline Q2 & $20819(31.8)$ & $23461(35.8)$ & $11941(18.2)$ & $9332(14.2)$ & \\
\hline Q3 & $24684(37.6)$ & $22754(34.6)$ & $10649(16.2)$ & 7643 (11.6) & \\
\hline Q4 & $20596(33.1)$ & $19529(31.4)$ & $10562(17.0)$ & $11471(18.5)$ & \\
\hline
\end{tabular}

${ }^{\mathrm{a} C h i-s q u a r e ~ t e s t . ~}$

Q, quartile.

The urbanization level was categorized by the population density of the residential area into 4 levels, with level 1 as the most urbanized and level 4 as the least urbanized. The daily average air pollutant concentrations were categorized into 4 groups based on quartiles for each air pollutant.

Values were expressed as $n(\%)$.

within the cohort of 254207 children from January 1, 2001 to December 31, 2012. The sociodemographic factors of participants are demonstrated in Table 1. The mean age of the participants was 6.43 years (SD, 3.38). The proportion of boys and girls were similar $(51.6 \%$ vs $48.4 \%)$. In the study population, there were more children living in higher population density areas (65.3\%).

According to the location of the Taiwan air quality monitoring station, we collected the data of participants without IBS history under conditions of $\mathrm{CO}, \mathrm{NO}_{2}, \mathrm{NMHC}$, and $\mathrm{CH}_{4}$ exposure, respectively. We categorized the concentrations of each air pollutant into 4 levels based on quartiles, ranging from Q1 (the lowest concentration) to Q4 (the highest concentration). Children with highest exposure concentrations of $\mathrm{CO}, \mathrm{NO}_{2}, \mathrm{NMHC}$, and $\mathrm{CH}_{4}$ lived in areas with higher urbanization. In contrast, children with the lowest exposure concentrations of $\mathrm{CO}, \mathrm{NO}_{2}$, and $\mathrm{NMHC}$ lived in areas with the lowest urbanization (Table 2).

The incidence rate for IBS increased with $\mathrm{CO}, \mathrm{NO}_{2}, \mathrm{NMHC}$, and $\mathrm{CH}_{4}$ exposure concentration, increasing from 0.84 to 1.76 , from 0.73 to 1.68 , from 0.85 to 1.98 , from 0.52 to 3.22 per 1000 person-years, respectively (Table 3). The Kaplan-Meier plots (Figure) with pollutant concentration stratified by quartile showed that patients exposed to higher pollution concentrations had higher accumulative incidence of IBS than those exposed to lower pollution concentrations of $\mathrm{CO}, \mathrm{NO}_{2}, \mathrm{NMHC}$, and $\mathrm{CH}_{4}$. In the multivariable Cox proportional hazard regression, the adjusted HR (adjusted for age, sex, monthly income, and urbanization level) for IBS increased with the $\mathrm{CO}, \mathrm{NO}_{2}, \mathrm{NMHC}$, and $\mathrm{CH}_{4}$ exposure concentrations from 0.83 to 1.98 , from 1.46 to 2.14 , from 1.13 to 2.19 , and from 1.37 to 5.87 , respectively, compared with those exposed to the corresponding concentrations in Q1 level. When we also adjusted the number of consultations/visits with a physician per year, and allergy diseases, the adjusted HR for IBS were still increased with the $\mathrm{CO}, \mathrm{NO}_{2}, \mathrm{NMHC}$, and $\mathrm{CH}_{4}$ exposure level from 0.75 to 1.88 , from 1.29 to 2.10 , from 1.06 to 2.23 , and from 1.45 to 6.02 , respectively (Table 3).

We divided our cohort into 2 groups: children with and without allergic diseases. The incidence rate and adjusted HR for IBS were significantly increased with the $\mathrm{CO}, \mathrm{NO}_{2}, \mathrm{NMHC}$, and $\mathrm{CH}_{4}$ 
Table 3. The Risk of Irritable Bowel Syndrome in Children Exposed to Various Air Pollutants Stratified by Quartile of Daily Average Concentration in Cox Proportional Hazard Regression

\begin{tabular}{|c|c|c|c|}
\hline Ambient air pollutants & IR & $\operatorname{HR}^{\mathrm{a}}(95 \% \mathrm{CI})$ & $\mathrm{HR}^{\mathrm{b}}(95 \% \mathrm{CI})$ \\
\hline \multicolumn{4}{|l|}{ Carbon monoxide (ppm) } \\
\hline $\mathrm{Q} 1,<0.56$ & 0.84 & Ref & Ref \\
\hline Q2, 0.56-0.67 & 0.69 & $0.83(0.72,0.96)^{\mathrm{c}}$ & $0.75(0.65,0.87)^{\mathrm{d}}$ \\
\hline Q3, $0.68-0.81$ & 1.51 & $1.74(1.53,1.97)^{\mathrm{d}}$ & $1.51(1.33,1.72)^{\mathrm{d}}$ \\
\hline $\mathrm{Q} 4,>0.81$ & 1.76 & $1.98(1.75,2.26)^{\mathrm{d}}$ & $1.88(1.66,2.14)^{\mathrm{d}}$ \\
\hline \multicolumn{4}{|l|}{ Nitrogen dioxide (ppb) } \\
\hline $\mathrm{Q} 1,<18.3$ & 0.73 & Ref & Ref \\
\hline Q2, 18.3-23.6 & 1.11 & $1.46(1.28,1.67)^{\mathrm{d}}$ & $1.29(1.13,1.48)^{\mathrm{d}}$ \\
\hline Q3, 23.7-26.9 & 1.31 & $1.70(1.50,1.94)^{\mathrm{d}}$ & $1.55(1.36,1.77)^{\mathrm{d}}$ \\
\hline $\mathrm{Q} 4,>26.9$ & 1.68 & $2.14(1.88,2.43)^{\mathrm{d}}$ & $2.10(1.85,2.39)^{\mathrm{d}}$ \\
\hline \multicolumn{4}{|l|}{ Non-methane hydrocarbon (ppm) } \\
\hline $\mathrm{Q} 1,<0.27$ & 0.85 & Ref & Ref \\
\hline $\mathrm{Q} 2,0.27-0.34$ & 0.96 & $1.13(1.01,1.26)^{\mathrm{c}}$ & $1.06(0.95,1.18)$ \\
\hline Q3, $0.35-0.50$ & 1.52 & $1.69(1.51,1.89)^{\mathrm{d}}$ & $1.58(1.41,1.76)^{\mathrm{d}}$ \\
\hline $\mathrm{Q} 4,>0.50$ & 1.98 & $2.19(1.97,2.43)^{\mathrm{d}}$ & $2.23(2.01,2.47)^{\mathrm{d}}$ \\
\hline \multicolumn{4}{|l|}{ Methane (ppm) } \\
\hline $\mathrm{Q} 1,<2.01$ & 0.52 & Ref & Ref \\
\hline Q2, 2.01-2.05 & 0.73 & $1.37(1.20,1.56)^{\mathrm{d}}$ & $1.45(1.27,1.65)^{\mathrm{d}}$ \\
\hline Q3, 2.06-2.11 & 1.14 & $2.09(1.85,2.36)^{\mathrm{d}}$ & $2.17(1.91,2.45)^{\mathrm{d}}$ \\
\hline $\mathrm{Q} 4,>2.11$ & 3.22 & $5.87(5.24,6.58)^{d}$ & $6.02(5.37,6.75)^{\mathrm{d}}$ \\
\hline
\end{tabular}

${ }^{a} \mathrm{HR}$, adjusted for age, sex, monthly income, and urbanization level.

${ }^{b} \mathrm{HR}$, adjusted for age, sex, monthly income, urbanization level, number of consultations/visits with a physician per year, and allergy diseases (atopic dermatitis, allergic rhinitis, and asthma).

${ }^{\mathrm{c}} \mathrm{P}<0.01,{ }^{\mathrm{d}} \mathrm{P}<0.001$

IR, incidence rate (per 1000 person-years); HR, hazard ratio; CI, confidence interval; Q, quartile; ppm, parts per million; ppb, parts per billion; Ref, reference group.

The daily average air pollutant concentrations were categorized into 4 groups based on quartiles for each air pollutant.

exposure concentrations in both groups (Supplementary Table 1). Baseline characteristics of participants exposed to each ambient air pollutant was listed in supplementary Tables 2-8. Comparisons of differences of incidences and associated hazard ratios for IBS in participants exposed various concentrations of air pollutants were listed in supplementary Table 9.

\section{Discussion}

Air pollution has become the greatest worldwide environmental health risk. ${ }^{8}$ Air pollution is a mixture of multiple substances including gaseous pollutants such as $\mathrm{CO}, \mathrm{NO}_{2}$, ozone, volatile organic compounds, and particulate matter $(\mathrm{PM}){ }^{18}$ Our results indicate that individuals that live in more urbanized areas had higher air pollutant $\left(\mathrm{CO}, \mathrm{NO}_{2}, \mathrm{NMHC}\right.$, and $\left.\mathrm{CH}_{4}\right)$ exposure, most likely due to the density of the vehicles and population being high in urban areas. Hence, the consumption of large amounts of energy and resources results in the emission of large amounts of air pollutants into the atmosphere in urban settings.

Air pollutants directly affect the respiratory system and cause pulmonary disorders such as asthma exacerbation. ${ }^{8}$ However, it is also associated with non-pulmonary diseases, including stroke, ${ }^{19}$ rheumatoid arthritis, ${ }^{16}$ and increased mortality of colon cancer patients. ${ }^{20}$ These findings implied that air pollutants do not only affect the respiratory system directly, but are also related to systemic inflammation.

A human study showed that air pollutants could enter the intestine directly through consumption of contaminated food and water. ${ }^{21}$ A previous study has demonstrated that more than $10^{12}$ microparticles were ingested per person daily in the western world. ${ }^{22}$ In addition, the inhaled particles were removed from the airway through mucociliary clearance, and then, swallowed in the GI tract. $^{23}$

Animal studies have suggested that exposure to air pollutants causes intestinal cell damage, accompanied with intestinal inflammation. Dybdahl et $\mathrm{al}^{24}$ showed that dietary exposure to diesels ex- 
A $\mathrm{CO}$

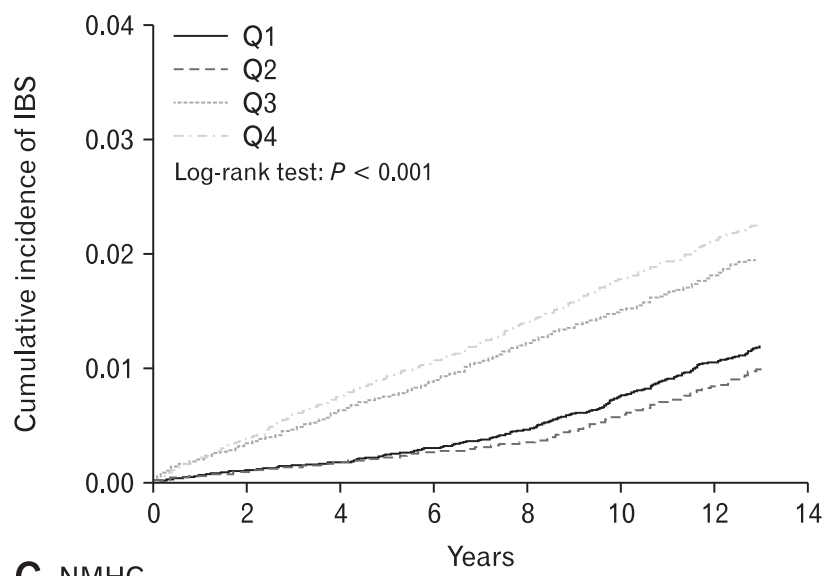

C NMHC

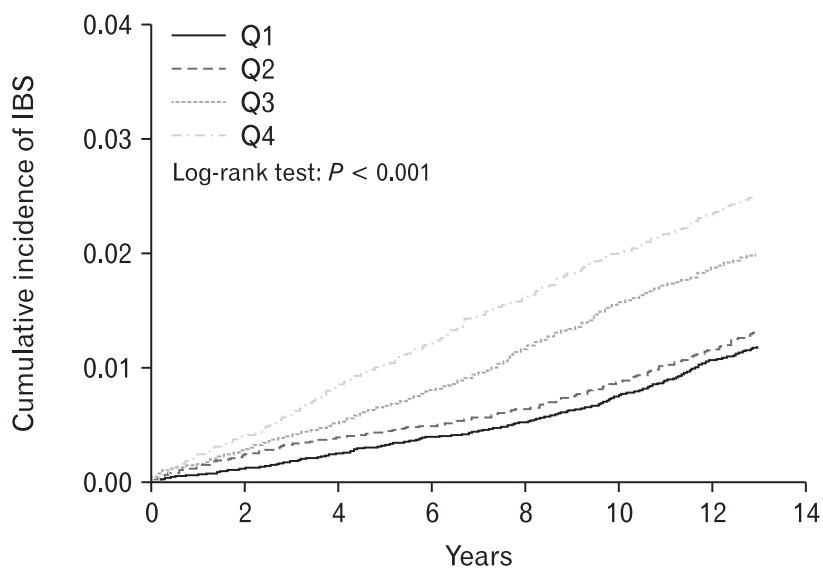

B $\mathrm{NO}_{2}$

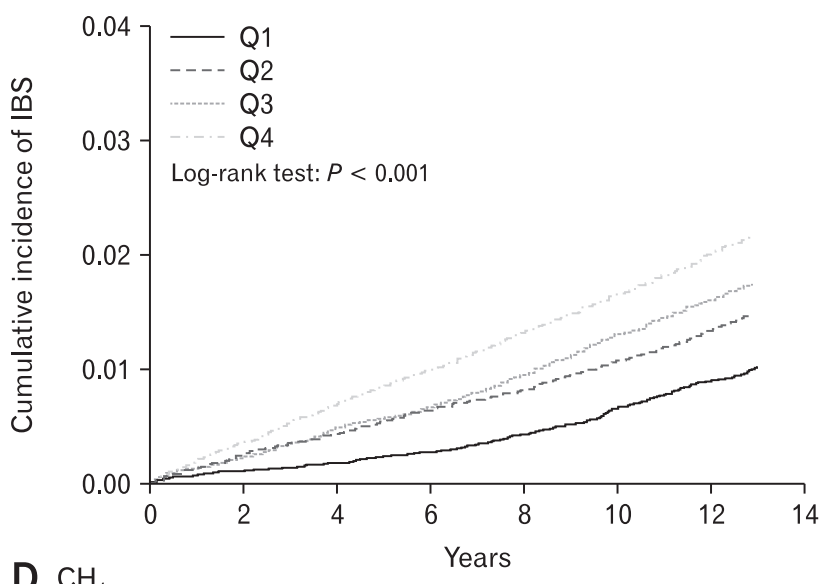

D $\mathrm{CH}_{4}$

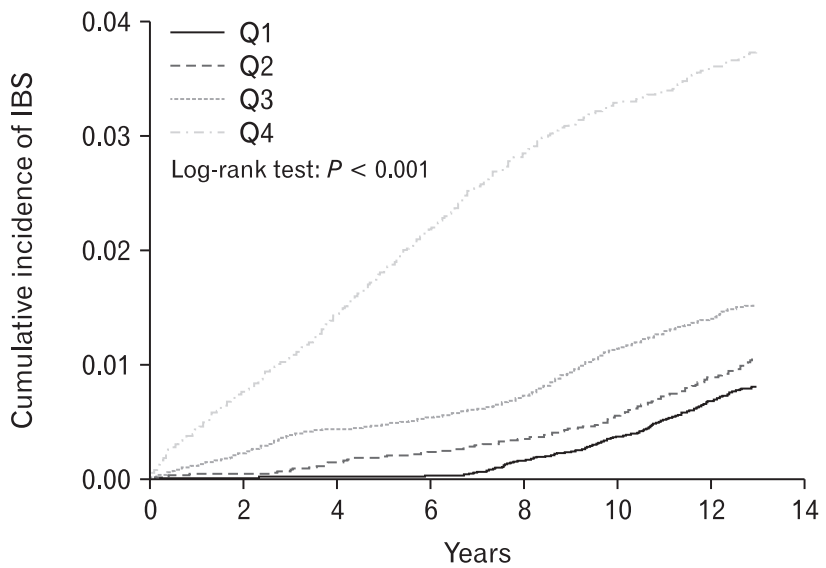

Figure. Kaplan-Meier curves of the accumulative incidence rate of irritable bowel syndrome (IBS) during the follow-up period among the different quartiles of each air pollutant. (A) Carbon monoxide (CO). (B) Nitrogen dioxide $\left(\mathrm{NO}_{2}\right)$. (C) Non-methane hydrocarbon (NMHC). (D) Methane $\left(\mathrm{CH}_{4}\right)$.

haust particles in rats, even in relatively low levels can cause DNA adducts and oxidative stress, results in DNA strand breaks, and apoptosis in colon mucosa. Kish et $\mathrm{al}^{25}$ found that GI exposure to $\mathrm{PM}$ in mice increased pro-inflammatory cytokine in both small and large intestine, and increased gut permeability. Mutlu et $\mathrm{al}^{26}$ also noted that GI exposure to high doses of PM in mice caused intestinal epithelial cell death, disruption of tight junction, increased gut permeability, and induced gut inflammation. These findings were compatible with human studies which demonstrated an impaired intestinal epithelial barrier and an increased intestinal permeability, with accompanying low-grade gut inflammation in patients with IBS. $^{27,28}$

The association between IBS and gut microbiome has been well established. ${ }^{29}$ Several animal studies have indicated that ingested air pollutants alter the gut microbiome. Kish et $\mathrm{al}^{25}$ showed that ingestion of PM in mice alters short chain fatty acid concentration in the colon and changed the percentage of Verrucomicrobia, Bacteroidetes, and Firmicutes. Salim et $\mathrm{al}^{30}$ demonstrated that Bifidobacterium was decreased in interleukin-10-deficient mice fed with PM. In addition, increased colonic pro-inflammatory cytokines, bacterial translocation into mesenteric lymph nodes, and increased serum lipopolysaccharide were also observed in those mice.

Furthermore, animal studies have also indicated the association between air pollution and GI motility. Roth and Tansy ${ }^{31}$ demonstrated that high concentration of gaseous air pollutants, including $\mathrm{CO}, \mathrm{NO}_{2}$, and ozone caused gastric contractility impairment in rats. Kaplan et $\mathrm{al}^{11}$ demonstrated that GI exposure to PM impaired colonic contractility, and increased pain response in mice.

Our data provide strong evidence on the association between air pollution exposure and IBS in children. These data show that children exposed to higher air pollutant concentration had increased risk of IBS (Table 3). The correlation is still noted after adjustment 
in monthly income, urbanization level, number of consultations/ visits with a physician per year, and allergy diseases. The finding indicated that crowed or stressful environment, and frequency of doctor's visit for other diseases were not a confounding factor in our study. The risk of IBS in both children with and without allergic diseases are also similar (Supplementary Table 1). Although a previous study has suggested that children with allergic disease may have higher risk of IBS, ${ }^{32}$ our data showed that the effect of air pollution in IBS was independent of allergic diseases.

The results are also consistent among various pollutants, although $\mathrm{CH}_{4}$ exposure results in the highest adjusted HR for IBS, compared with other pollutants. Several studies have indicated the correlation between $\mathrm{CH}_{4}$ and GI motility. $\mathrm{CH}_{4}$ may slow down intestinal transit time, ${ }^{33,34}$ augments small intestinal contractile activity, ${ }^{34}$ and is associated with constipation-predominant IBS. ${ }^{35}$ However, there is still lack of research focused on the association between other pollutants and IBS or other functional GI disorders.

Kaplan et $\mathrm{al}^{11}$ have reported that the frequency of emergency department visits for non-specific abdominal pain in young individuals 15-24 years old was associated with the concentration of air pollutants. To the best of our knowledge, our study is the first one to suggest the correlation between air pollution and IBS in children. There are several strengths in this study. First, our cohort is a national-based cohort, with a large sample size and long-term followup. Moreover, the IBS diagnosis was determined by a physician and not using self-reported questionnaires completed by patients or their parents.

On the other hand, potential limitations that could serve as confounders to this study should be acknowledged. First, genetic and behavioral factors, severity and subtype of IBS were not captured in administrative claims databases. Second, children with higher exposure of air pollution lived in areas with higher urbanization. Children living in more crowded environment might have higher stress associated with more crowded housing. Moreover, children in more polluted areas may have more non-GI diseases and consultations for respiratory tract infections and allergic diseases. The more frequent that a child consults the doctor has more opportunities of being diagnosed with IBS. Thus, we had adjusted for possible confounders. Even though we adjusted for these variables statistically, the bias cannot be eliminated thoroughly. Such limitation is inevitable in an observational study. Third, coding accuracy and financial incentives may lead to bias when using ICD-9 codes for diagnosis in large insurance claims data for research. Fourth, data from fixed monitoring stations may not reflect the true exposure level to air pollutants in patients. Fifth, some studies ${ }^{36,37}$ had noted less consul- tation for pediatric functional abdominal pain disorders during the summer. However, in this study design, we used the daily average air pollutant concentrations, and seasonal variation of air pollutant concentration was not found. Previous study showed that the prevalence of IBS in children was ranges from $2.8 \%$ to $14 \%{ }^{38,39}$ The prevalence varies because considerable heterogeneity exists between studies in methodology, study population and the use of different diagnostic criteria to define IBS. However, all these data are prevalence, not the incidence of IBS. Our data showed the incidence rate for IBS increased with $\mathrm{CO}, \mathrm{NO}_{2}, \mathrm{NMHC}$, and $\mathrm{CH}_{4}$ exposure concentration, increasing from 0.84 to 1.76 , from 0.73 to 1.68 , from 0.85 to 1.98 , from 0.52 to 3.22 per 1000 person-years, respectively.

In conclusion, our study is the first study to demonstrate that long-term exposure to ambient air pollutants is a potential risk factor for childhood IBS. Exposure to high level of gaseous air pollutants $\left(\mathrm{CO}, \mathrm{NO}_{2}, \mathrm{NMHC}\right.$, and $\left.\mathrm{CH}_{4}\right)$, especially $\mathrm{CH}_{4}$, is significantly associated with the development of childhood IBS. Our results suggest the effects of air pollution on GI diseases, but further investigation on this issue is still needed.

\section{Supplementary Materials}

Note: To access the supplementary tables mentioned in this article, visit the online version of Journal of Neurogastroenterology and Motility at http://www.jnmjournal.org/, and at https://doi. org/10.5056/jnm18135.

Financial support: This work was supported partly by grants from the Ministry of Health and Welfare, Taiwan (MOHW107TDU-B-212-123004), China Medical University Hospital (DMR-108-200), China Medical University Hospital, Academia Sinica Stroke Biosignature Project (BM10701010021), the Ministry of Science and Technology, Taiwan (MOST 107-2314-B039-037-), Tseng-Lien Lin Foundation, Taichung, Taiwan, and Katsuzo and Kiyo Aoshima Memorial Funds, Japan.

\section{Conflicts of interest: None.}

Author contributions: Miguel Saps and Chang-Ching Wei conceptualized and designed the study, coordinated and supervised data collection, critically reviewed the manuscript, and approved the final manuscript as submitted; Teck-King Tan drafted the initial manuscript; and Cheng-Li Lin carried out the analysis, reviewed and approved the final manuscript as submitted. 


\section{References}

1. Rasquin A, Di Lorenzo C, Forbes D, et al. Childhood functional gastrointestinal disorders: child/adolescent. Gastroenterology 2006;130:15271537.

2. Varni JW, Lane MM, Burwinkle TM, et al. Health-related quality of life in pediatric patients with irritable bowel syndrome: a comparative analysis. J Dev Behav Pediatr 2006;27:451-458.

3. Zhou H, Li D, Cheng G, Fan J, Lu H. An epidemiologic study of irritable bowel syndrome in adolescents and children in south China: a school-based study. Child Care Health Dev 2010;36:781-786.

4. Son YJ, Jun EY, Park JH. Prevalence and risk factors of irritable bowel syndrome in Korean adolescent girls: a school-based study. Int J Nurs Stud 2009;46:76-84.

5. Baber KF, Anderson J, Puzanovova M, Walker LS. Rome II versus Rome III classification of functional gastrointestinal disorders in pediatric chronic abdominal pain. J Pediatr Gastroenterol Nutr 2008;47:299-302.

6. Walker LS, Lipani TA, Greene JW, et al. Recurrent abdominal pain: symptom subtypes based on the Rome II criteria for pediatric functional gastrointestinal disorders. J Pediatr Gastroenterol Nutr 2004;38:187-191.

7. Bellini M, Gambaccini D, Stasi C, Urbano MT, Marchi S, Usai-Satta P. Irritable bowel syndrome: a disease still searching for pathogenesis, diagnosis and therapy. World J Gastroenterol 2014;20:8807-8820.

8. Künzli N, Kaiser R, Medina S, et al. Public-health impact of outdoor and traffic-related air pollution: a European assessment. Lancet 2000;356:795-801.

9. Ananthakrishnan AN, McGinley EL, Binion DG, Saeian K. Ambient air pollution correlates with hospitalizations for inflammatory bowel disease: an ecologic analysis. Inflamm Bowel Dis 2011;17:1138-1145.

10. Orazzo F, Nespoli L, Ito K, et al. Air pollution, aeroallergens, and emergency room visits for acute respiratory diseases and gastroenteric disorders among young children in six Italian cities. Environ Health Perspect 2009;117:1780-1785.

11. Kaplan GG, Szyszkowicz M, Fichna J, et al. Non-specific abdominal pain and air pollution: a novel association. PLoS One 2012;7:e47669.

12. Davis K, Huang AT. Learning from Taiwan: experience with universal health insurance. Ann Intern Med 2008;148:313-314.

13. Cheng TM. Taiwan's national health insurance system: high value for the dollar. Six countries, six reform models--the healthcare reform experience of Israel, the Netherlands, New Zealand, Singapore, Switzerland and Taiwan. Hackensack, NJ: World Scientific 2009:171-204

14. Wu CS, Lai MS, Gau SS, Wang SC, Tsai HJ. Concordance between patient self-reports and claims data on clinical diagnoses, medication use, and health system utilization in Taiwan. PLoS One 2014;9:e112257.

15. Wei CC, Lin CL, Kao CH, et al. Increased risk of Kawasaki disease in children with common allergic diseases. Ann Epidemiol 2014;24:340343.

16. Liu CY, Hung YT, Chuang YL, et al. Incorporating development stratification of Taiwan townships into sampling design of large scale health interview survey. J Health Manag 2006;4:1-22.
17. Chang $\mathrm{KH}, \mathrm{Hsu} \mathrm{CC}$, Muo $\mathrm{CH}$, et al. Air pollution exposure increases the risk of rheumatoid arthritis: a longitudinal and nationwide study. Environ Int 2016;94:495-499.

18. Schwela D. Air pollution and health in urban areas. Rev Environ Health 2000;15:13-42.

19. Villeneuve PJ, Chen L, Stieb D, Rowe BH. Associations between outdoor air pollution and emergency department visits for stroke in Edmonton, Canada. Eur J Epidemiol 2006;21:689-700.

20. Gorham ED, Garland CF, Garland FC. Acid haze air pollution and breast and colon cancer mortality in 20 Canadian cities. Can J Public Health 1989;80:96-100.

21. European Commission Scientific Committee on Food. Opinion on the scientific committee on food on the risk to human health of polycyclic aromatic hydrocarbons in food. Available from URL: https:/ec.europa. eu/food/sites/food/files/safety/docs/sci-com_scf_out153_en.pdf (accessed 8 March, 2019).

22. Lomer MC, Thompson RP, Powell JJ. Fine and ultrafine particles of the diet: influence on the mucosal immune response and association with Crohn's disease. Proc Nutr Soc 2002;61:123-130.

23. Möller W, Häussinger K, Winkler-Heil R, et al. Mucociliary and longterm particle clearance in the airways of healthy nonsmoker subjects. J Appl Physiol (1985) 2004;97:2200-2206.

24. Dybdahl M, Risom L, Møller P, et al. DNA adduct formation and oxidative stress in colon and liver of Big Blue rats after dietary exposure to diesel particles. Carcinogenesis 2003;24:1759-1766.

25. Kish L, Hotte N, Kaplan GG, et al. Environmental particulate matter induces murine intestinal inflammatory responses and alters the gut microbiome. PLoS One 2013;8:e62220.

26. Mutlu EA, Engen PA, Soberanes S, et al. Particulate matter air pollution causes oxidant-mediated increase in gut permeability in mice. Part Fibre Toxicol 2011;8:19.

27. Martínez C, Lobo B, Pigrau M, et al. Diarrhoea-predominant irritable bowel syndrome: an organic disorder with structural abnormalities in the jejunal epithelial barrier. Gut 2013;62:1160-1168.

28. Piche T, Barbara G, Aubert P, et al. Impaired intestinal barrier integrity in the colon of patients with irritable bowel syndrome: involvement of soluble mediators. Gut 2009;58:196-201.

29. Kennedy PJ, Cryan JF, Dinan TG, Clarke G. Irritable bowel syndrome: a microbiome-gut-brain axis disorder? World J Gastroenterol 2014;20:14105-14125.

30. Salim SY, Jovel J, Wine E, et al. Exposure to ingested airborne pollutant particulate matter increases mucosal exposure to bacteria and induces early onset of inflammation in neonatal IL-10-deficient mice. Inflamm Bowel Dis 2014;20:1129-1138.

31. Roth RP, Tansy MF. Effects of gaseous air pollutants on gastric secretomotor activities in the rat. J Air Pollut Control Assoc 1972;22:706-709.

32. Tan TK, Chen AC, Lin CL, Shen TC, Li TC, Wei CC. Preschoolers with allergic diseases have an increased risk of irritable bowel syndrome when reaching school age. J Pediatr Gastroenterol Nutr 2017;64:26-30.

33. Soares AC, Lederman HM, Fagundes-Neto U, de Morais MB. Breath methane associated with slow colonic transit time in children with chronic constipation. J Clin Gastroenterol 2005;39:512-515. 
34. Pimentel M, Lin HC, Enayati P, et al. Methane, a gas produced by enteric bacteria, slows intestinal transit and augments small intestinal contractile activity. Am J Physiol Gastrointest Liver Physiol 2006;290:G1089-G1095.

35. Chatterjee S, Park S, Low K, Kong Y, Pimentel M. The degree of breath methane production in IBS correlates with the severity of constipation. Am J Gastroenterol 2007;102:837-841.

36. Saps M, Hudgens S, Mody R, Lasch K, Harikrishnan V, Baum C. Seasonal patterns of abdominal pain consultations among adults and children. J Pediatr Gastroenterol Nutr 2013;56:290-296.

37. Pollard KL, Campbell C, Squires M, Palsson O, van Tilburg MAL.
Seasonal association of pediatric functional abdominal pain disorders and anxiety. J Pediatr Gastroenterol Nutr 2018;67:18-22.

38. Devanarayana NM, Rajindrajith S, Pathmeswaran A, Abegunasekara C, Gunawardena NK, Benninga MA. Epidemiology of irritable bowel syndrome in children and adolescents in Asia. J Pediatr Gastroenterol Nutr 2015;60:792-798.

39. Karabulut GS, Beşer OF, Erginöz E, Kutlu T, Cokuğraş FÇ, Erkan T. The incidence of irritable bowel syndrome in children using the Rome III criteria and the effect of trimebutine treatment. J Neurogastroenterol Motil 2013;19:90-93. 